\title{
Genetic Diversity and Pathogenicity of Metarhizium spp. Associated with the White Grub Phyllophaga capillata (Blanchard) (Coleoptera: Melolonthidae) in a Soybean Field
}

\author{
RB Lopes ${ }^{1}$, DA SOUzA ${ }^{1}$, CM OliveIRA $^{2}$, M FARIA $^{1}$ \\ 'EMBRAPA Recursos Genéticos e Biotecnologia, Brasília, DF, Brasil \\ ${ }^{2}$ EMBRAPA Cerrados, Planaltina, DF, Brasil
}

\section{Keywords}

Entomopathogenic fungi, Metarhizium diversity, Metarhizium robertsii, microbial control, molecular characterization

\section{Correspondence}

M Faria, EMBRAPA Recursos Genéticos e Biotecnologia, Parque Estação Biológica, W5 Norte, CEP 70770-917, Brasília, DF, Brasil; marcos.faria@embrapa.br

Edited by Ítalo Delalibera Jr - ESALQ/USP

Received 19 October 2012 and accepted 27 May 2013

Published online 19 June 2013

(C) Sociedade Entomológica do Brasil 2013

\begin{abstract}
Phyllophaga capillata (Blanchard) was recently described as a soybean pest in Brazil. The occurrence of Metarhizium spp. associated with adults and their pathogenicity were investigated. Natural prevalence of Metarhizium anisopliae was $0.51 \%$ in adults collected by light trap. Most Metarhizium isolates were identified as Metarhizium robertsii, although $M$. anisopliae sensu stricto and a few unidentified isolates were also found. Bioassays with representative isolates selected from different genetic groups resulted in $\leq 5.6 \%$ confirmed mortality against larvae and adults, suggesting low potential of microbial control of this pest by use of indigenous Metarhizium isolates.
\end{abstract}

White grubs in the genus Phyllophaga have been reported to be among the most destructive pests in Central and South America (Morón 1997). Phyllophaga capillata (Blanchard) was recently described as a rhizophagous soybean pest in Middle-Western Brazil (Oliveira et al 2007). In the present study, we evaluated the natural prevalence of entomopathogenic fungi associated with $P$. capillata adults and their genetic diversity, as well as the pathogenicity of indigenous Metarhizium isolates against the adult and larval stages.

Phyllophaga capillata adults were collected in October 2010 from a soybean field in the state of Goiás following emergence using a light trap set up on a white cloth, and put inside plastic containers filled with soil sample (20$50 \mathrm{~cm}$ deep) collected near the trap. In the laboratory, adults remained in soil for a 20-day incubation period at room temperature and every 2 days, dead insects were removed and transferred to wet chambers. Insectassociated fungi were isolated and cultivated on PDA medium for a 10 -day incubation period at $25 \pm 0.5^{\circ} \mathrm{C}$. A total of 2,556 P. capillata adults were collected and 13 insects were infected by Metarhizium anisopliae (s.l.).
Phylogenetic analyses were used to assess the genetic variability of these isolates. Total genomic DNA was extracted from mycelia using the protocol described by Raeder \& Broda (1985). Identification was performed by amplifying the TEF-1 $\alpha$ gene fragment based on Bischoff et al (2009). Analyses of the consensus sequences were carried out under the Maximum Likelihood method and bootstrap support (BS) values were provided. Additionally, we used Bayesian phylogenetic inference and BS values were included in the Bayesian tree. One major group aggregating eight isolates was confirmed as Metarhizium robertsii. In the second group, two isolates were identified as $M$. anisopliae sensu stricto (s.s.), clearly clustering with sequences from the GenBank database (Fig 1). The three remaining isolates (CG1231, CG1233, and CMA12) were closest to M. anisopliae (s.s.) (98.98\% of similarity with ARSEF7487), although additional studies are required before any definitive identification is made. Likewise, Rocha et al (2012) reported the isolation of $M$. robertsii, $M$. anisopliae (s.s.), and over 50 unidentified Metarhizium isolates from soil samples in Central Brazil. Interestingly, in a survey conducted by our team in a near municipality, another 
Metarhizium species (Metarhizium lepidiotae, also included in Fig 1) was isolated from the melolonthid Aegopsis bolboceridus (Thomson) in a corn field. In contrast to $M$. anisopliae (s.s.) and M. robertsii (Faria et al 2010, XavierSantos et al 2011), this is the first record of $M$. lepidiotae infecting an insect in Brazil. Accession numbers in GenBank for Metarhizium isolates incorporated in the Invertebrate Fungal Collection at EMBRAPA Genetic Resources and Biotechnology are KC832295 (M. anisopliae CG1232), KC832294 (M. anisopliae s.l. CG1231), KC832296 (M. anisopliae s.l. CG1233), KC832297 (M. robertsii CG1234), and KC832298 (M. lepidiotae CG1238).
Third-instars larvae from the same soybean site, extracted from soil a few months later (February/2011), were immersed in conidial suspensions $\left(1 \times 10^{7}\right.$ viable conidia $\left.\mathrm{mL}^{-1}\right)$ or water. Four representative isolates were selected from different genetic groups [one $M$. robertsii, one $M$. anisopliae (s.s.), and two M. anisopliae (s.l.)]. For each isolate, six groups of 10 insects were confined in 1,000-mL round plastic containers filled with soil and soybean seedlings as food source, and kept in a room at $25 \pm 2^{\circ} \mathrm{C}$ and $70 \% \mathrm{RH}$. Mortality was assessed at 20-day post-inoculation. For bioassays with adults, individuals collected in the field 1 year later (October-November 2011) were observed for 20 days

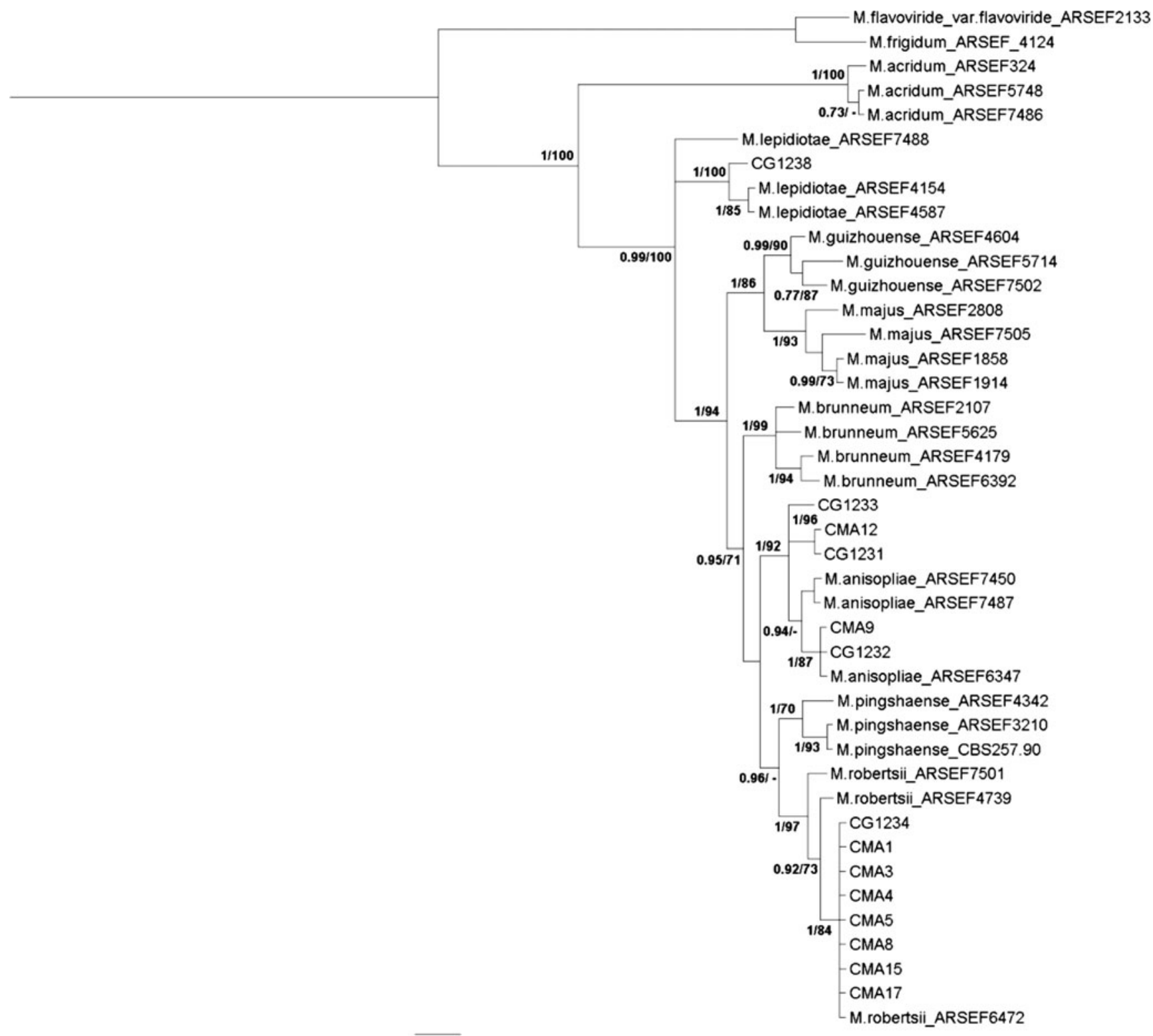

Fig 1 Bayesian majority rule consensus phylogram of aligned 5' end of TEF-1 $\alpha$ gene sequence data for Metarhizium isolates. Sequence data from ARSEF isolates are from the GenBank database, whereas non-ARSEF isolates (coded CG or CMA) correspond to those from Phyllophaga capillata adults collected in October 2010 in state of Goiás, Brazil (exception is CG1238, isolated from an adult of the melolonthid Aegopsis bolboceridus). 
and then inoculated on the thorax with $5 \mu \mathrm{L}$ of conidial suspensions $\left(5 \times 10^{7}\right.$ viable conidia $\left.\mathrm{mL}^{-1}\right)$ or water (control), using a glass micro syringe coupled to a micro applicator. Following inoculation, six groups of 12 insects ( 4 males and 8 females) were transferred to $1,000-\mathrm{mL}$ round plastic containers and incubated as previously described. A tubular plastic cage with a screened lid was used on top of each container to allow insect movement at night (mating behavior) and to avoid escape. Mortality was assessed at 12-day post-inoculation. In general, Metarhizium isolates tested against $P$. capillata were not pathogenic or caused very low levels of confirmed mortality ( $\leq 5.6$ and $\leq 1.7 \%$ for adults and larvae, respectively), whereas fungal infections were not seen in non-treated insects (data not shown). Mortality of the larval stage of the melolonthid Phyllophaga sp. treated with different Metarhizium spp. isolates was less than $20 \%$ after a 36 -day incubation period and using the same dipping methodology adopted in our work, although their conidial concentration was 10x higher (GuzmánFranco et al 2012).

In summary, we identified at least two Metarhizium species associated with $P$. capilatta adults within the same population, although natural infection was low. Besides, $P$. capilatta adults and larvae showed low susceptibility to fungal infections under laboratory conditions.
Acknowledgments We appreciate the funding provided by the Brazilian National Research Council (CNPq).

\section{References}

Bischoff JF, Rehner SA, Humber RA (2009) A multilocus phylogeny of the Metarhizium anisopliae lineage. Mycologia 101:508-528

Faria M, Hotchkiss JH, Hajek AE, Wraight SP (2010) Debilitation in conidia of the entomopathogenic fungi Beauveria bassiana and Metarhizium anisopliae and implication with respect to viability determinations and mycopesticide quality assessments. J Invertebr Pathol 105:74-83

Guzmán-Franco AW, Hernández-López J, Enríquez-Vara JN, AlatorreRosas R, Tamayo-Mejía F, Ortega-Arenas LD (2012) Susceptibility of Phyllophaga polyphylla and Anomala cincta larvae to Beauveria bassiana and Metarhizium anisopliae isolates, and the interaction with soil properties. BioControl 57:553-563

Morón MA (1997) White grubs (Coleoptera: Melolonthidae: Phyllophaga Harris) in Mexico and Central America. A brief review. Trends Entomol 1:117-128

Oliveira CM, Morón MA, Frizzas MR (2007) First record of Phyllophaga sp. aff. capillata (Coleoptera: Melolonthidae) as a soybean pest in the Brazilian "Cerrado". Fla Entomol 90:772-775

Raeder U, Broda P (1985) Rapid preparation of DNA from filamentous fungi. Lett Appl Microbiol 1:17-20

Rocha LF, Inglis PW, Humber RA, Kipnis A, Luz C (2012) Occurrence of Metarhizium spp. in Central Brazilian soils. J Basic Microbiol 52:1-10

Xavier-Santos S, Lopes RB, Faria M (2011) Emulsifiable oils protect Metarhizium robertsii and Metarhizium pingshaense conidia from imbibitional damage. Biol Control 59:261-267 